\title{
The Effect of Dynamic Written Corrective Feedback on Iranian Elementary Learners' Writing
}

\author{
Amaneh Kamalian \\ Department of Foreign Languages \\ Sciences and Researches Branch \\ Islamic Azad University, Fars, Iran \\ E-mail: Amaneh.kamalian@gmail.com \\ Anita Lashkarian (Corresponding author) \\ Department of English, Meibod Branch, Islamic Azad University, Iran \\ E-mail: anitalashkarian@yahoo.com
}

Received: 06-03-2014

doi:10.7575/aiac.ijalel.v.3n.5p.47
Accepted: 29-04-2014

Published: 01-09-2014

URL: http://dx.doi.org/10.7575/aiac.ijalel.v.3n.5p.47

\begin{abstract}
Error correction is probably the most widely used technique for responding to students' writing. Although many studies have attempted to investigate the efficacy of providing error correction through different types of written corrective feedback (WCF), there has been relatively little research on any one new approach to writing pedagogy in foreign language learning which is called dynamic WCF. The purpose of the current research was to test the effect of WCF on the improvement of writing abilities of EFL learners. Two groups of EFL students who were learning English as a foreign language participated in this study. Both groups (A and B) were given treatments. Core components of the treatment included having the students to write a composition every session (twice a week) and the teacher providing the students with feedbacks (dynamic WCF or direct WCF) on their writing tasks. Group A ( $\mathrm{n}=24$ ) was instructed through dynamic WCF because it was intended to improve L2 writing ability in general by raising linguistic awareness of learners through the error corrections performed by the teacher. On the other hand, group B ( $\mathrm{n}=22$ ) received direct WCF on their writings. Four essential characteristics were taken into consideration for the error correction, i.e. feedback needed to be manageable, meaningful, timely and constant. The data obtained for Group A and Group B was analyzed using paired sample test and the results indicated that both groups had improved on their writing abilities. Also, administrating an independent sample T-test the findings revealed that Group A which received dynamic WCF could outperform Group B.
\end{abstract}

Keywords: corrective feedback; dynamic written corrective feedback; direct error correction

\section{Introduction}

A foreign language writing teacher plays a significant role in improving the proficiency of his/her students' writing in accordance with the students' needs and course objectives. However, most of the teachers agree that responding to students' writing is one of the most challenging parts of their job. Many foreign language teachers believe that checking students written assignments and providing feedback is time-consuming and boring. Nevertheless, providing written corrective feedback (WCF) has been widespread among them. On the other hand, it appears that students consider their teacher's written feedback as the most important component that will contribute to their success. But how to make the best of them is still an unanswered problem. Sometimes students receive a huge amount of feedback on their writing which is vague and ambiguous for them to understand. This may decrease students' motivation to write more. Seemingly, a group of students even do not pay attention to the teacher's comments and throw it in the waste basket without considering their mistakes and the feedback from the teacher. This has been a problem in many writing classes that needs to be solved. In this connection, providing suitable error correction (EC) may be beneficial depending on the level of students, type of errors and the context where students are learning English.

Error correction is one type of feedback that English as foreign language (EFL) writing teachers provide. Perhaps it is the most widely used method to respond to the student writing. Ferris (2004) states that for teachers error correction represents spending a huge amount of time as writing instructors and for students, it may be the most important to improve their writing (Corpuz, 2011).

Over the last decade, considerable attention has been given to the treatment of error and EC in Second/Foreign language learners' writings. However, there is still no agreement on how teachers can best react to their students errors.

Seemingly, error correction as one of the most disgusting and frustrating experiences of teachers has generated much controversy in foreign language teaching. A possible explanation appears to be teachers' assumption about the efficacy of the feedback and the steps writing instructors can utilize to help their students improve on their writing. 
A key issue concerning the efficacy of written corrective feedback was defined by Ferris (2004): "Does written corrective feedback help students to improve in writing over time?" Sheen (2007) states that this question has not been answered yet because past researches have failed to provide unambiguous evidence of the effectiveness of written corrective feedback. There have been a large number of studies that have questioned whether errors related to writing should be corrected or not. Some researchers like (Truscott, 1996; Ferris, 1999; Chandler, 2003) debated the effectiveness of error correction and its contribution to the improvement of writing accuracy. In contrast, some have investigated the efficacy of WCF ( Bitchener \& Knoch, 2008; Chandler, 2003; Sheen, 2007). What makes the issue even more controversial is the variety of strategies for carrying out written corrective feedback -e.g. Direct, indirect and metalinguistic corrective feedback.

Many studies like (Ashwell, 2000; Chandler, 2003; Ferris \& Hedgcock, 2005) reveal that teachers and L2 writing researchers have favored the use of indirect feedback that is errors are indicated and students are asked to correct the errors by themselves. Relatively few studies have investigated the efficacy of direct feedback that is where learners are given the correction. Metalinguistic corrective feedback, on the other hand provides explicit (direct) comments about the nature of errors that have been made. Commonly the most favorable type is using error codes. This technique refers to utilizing correction codes ( $\mathrm{S} . \mathrm{V}=$ subject-verb agreement, $\mathrm{PL}=$ plural, $\mathrm{SING}=$ singular and etc.) to inform the $\mathrm{L} 2$ student that not only an error has been made, but also shed light on the type of error( for more detailed examples of error correction codes, see Appendix 1).

Although there are various strategies concerning error correction on writing, it still remains ambiguous which written corrective feedback strategy can be more helpful to the Learners. Teachers tend to provide students with WCF on the assumption that it will improve students' writing. Actually, they are looking for a positive change which is the essential reason for giving feedback, and if it has been helpful, then a student has learned or has the opportunity to learn. This objective may happen only when the students have meaningful opportunities to learn. Otherwise, writing may be changed into a tedious and frustrating job for the students.

To overcome such problems, a new strategy has been introduced by Hartshorn (2008) based on insights achieved from research and theory which is called dynamic WCF. It is called dynamic because it can refer to "an interactive system or process" marked by "continuous change, activity or progress" (Hartshorn et al. 2010, p.87).This type of error correction has two essential elements that students need to maximize- individual learner needs and a pedagogical approach that will ensure that the writing tasks and feedback are meaningful, timely, constant and manageable for both students and teachers (Hartshorn, 2008). This feedback has been chosen for the present study as the researcher believes it can be more helpful in enhancing the accuracy level of learners' writing in comparison to the other strategies.

\subsection{Review of the related literature}

Dynamic corrective feedback based on insights achieved from research and theory is a new instructional methodology for improving accuracy of students' writing.( Evans et. al. 2010). There are four aspects in dynamic WCF. Each of these aspects is addressed below based on Evans et. al., (2010).

\subsubsection{Meaningfulness}

In order to show that feedback is meaningful to the learners at a cognitive level, indirect feedback is used in the form of coded symbols. Using coded symbols, a teacher can show the error type and its location. Then, it's the student writer to correct the identified mistakes. Students are taught how to interpret the symbols and keep track of errors on Tally sheet (see Appendix 2). Tally sheet is a cumulative list of errors that show frequencies for each error type. This tool may raise the student awareness and can be used to identify high-frequency errors, which form the basis for explicit instruction essential to skill acquisition theory (Evans. et.al. 2010).

\subsubsection{Timelyness and constant}

Based on skill acquisition theory, in order for the feedback to be meaningful, it also needs to be timely and constant. In dynamic WCF, feedback is timely when the student writing is consistently marked with coded symbols and returned to them the following session. It is constant when students produce new process of writing and receive feedback from teacher nearly every session of the course. The researcher of the study was very meticulous about this part of dynamic corrective feedback and did her best to correct the students' paper as soon as possible and return them the next class. She also thinks that her approach was constant, the reason being that students produced new writings each sessions and received feedback from their teacher.

\subsubsection{Manageability}

Another vital aspect of the feedback is that, it must be manageable. According to Evans et.al (2010), feedback is manageable for teachers when they have enough time to attend to the quality and completeness of what they communicate to their students. On the other hand, it is manageable for the students when they have time and ability to process, learn from and apply the feedback they have received from their teacher. The aspect of manageability in ESL writing practice has not been largely mentioned in previous studies. But recently, Bitchener (2008, cited in Evans et.al 2010) has highlighted the importance of giving feedback to prevent "informal overload". He suggests that teachers and students focus on one or a few error types at a time. Although some researchers like (Ferris, 2006; Sheen 2007) have largely advocated this view, it may be much less practical for a classroom of students who are worried to improve the overall accuracy of their writing. Such an approach would be problematic because the error categories specified for the feedback do not show the most frequent error types produced by individual students. Additionally, focusing only on a 
few limited error type seems at odds with the notions of effective practice suggested by researcher such as Ranta $\&$ Lyster (2007, p.151, cited in Evans et.al. 2010) who advocated a practice that is inherently repetitive and psychologically authentic.

Therefore, to ensure that the task and feedback are manageable in dynamic WCF, simply length of students' writing should be limited. With a shorter piece of writing, teachers have enough time to identify all linguistic errors without overwhelming themselves or their students. Thus, 15 minute paragraph writing is considered nearly each session. 15 minutes is chosen because it is long enough to provide a sample of writing while still being manageable for the teacher to check the papers.

Many studies have been conducted on the issue of corrective codes. Among them, a study by Sevgi and Dogan (2007) investigated the possible effects of direct and indirect coded error feedback in a Turkish university context with regard to accuracy in writing. Considering two groups of pre-intermediate level students, one group received direct feedback, i.e., the correct form of was written on students' paper and the other group received indirect coded feedback, i.e., a symbol representing a specific kind of error for the indication of the error. The result of the study revealed that while an overall comparison of the groups for the whole treatment period did not yield any statistically significant differences, the indirect coded feedback group committed fewer errors than the direct feedback group.

Seemingly, in Mahmoud's (2000) study the efficacy of corrective symbols was proved. The research was conducted on 102 Arabic-speaking EFL university students and they were asked to indicate the technique of feedback they preferred. The techniques were: 1) mere indication of the location of deviation, 2) writing correction codes or symbols, 3) giving rules and explanations leading to the correct forms, 4) direct correction by writing correct forms. Interestingly, he found that most of the students (99 of them) preferred the use of correction codes. These 99 students, as he claims, unanimously said they wanted to be given the chance to correct their deviation themselves.

To shed more light on the efficacy of dynamic WCF, it is worth mentioning that Hartshorn (2008) in his study tried to determine the effect of one approach to writing pedagogy on L2 writing accuracy. Utilizing two groups, the control group was taught with traditional process writing while the treatment group was taught with an innovative approach that aimed to improve writing accuracy by raising learners' awareness through error correction. This was achieved through a systematic method where students wrote 10 minutes each day and received coded corrective feedback on their writing. The result of the study showed that L2 writers may benefit the most when the feedback designed to improve their linguistic accuracy is manageable, meaningful, timely and constant (dynamic WCF).

Moreover, Evans et. al.,(2010) conducted a study investigating the efficacy of the same innovative instructional methodology specifically designed to improve L2 writing accuracy. In order to test if Dynamic WCF might work, a pilot study was run in two separate advanced-low ESL Applied Grammar (AG) classes in two separate semesters. 27 students were divided into two groups. One group received Dynamic WCF and the other one was given direct feedback on their writing. The result of the study revealed that the students who were given Dynamic WCF had better performance. However, Evans et. al., (2010) mention that they the result of the study must be evaluated with caution because no control group was used.

Finally, in a recent study by Evans, Hartshorn and Dian (2011) the efficacy of dynamic WCF was tested in the context of students who were enrolled in university undergraduate studies. A comparative study was conducted measuring ESL learners who were taught writing using dynamic WCF against who received traditional process writing instruction. Results indicated that the students who received traditional process writing instruction experienced some declines in linguistic accuracy while those who received Dynamic WCF showed significant improvement in their linguistic accuracy of their L2 writing.

Uncertainty still prevails as to whether this new corrective feedback approach is practical in all contexts especially in the present context. In consequence, the researcher chose dynamic WCF to see if it leaves any influence on Iranians' writing accuracy. One also should not overlook the fact that in order to investigate the effectiveness of this approach enough attention should be paid to that four characteristics, i.e., the given feedback should be timely, constant, meaningful and manageable.

\subsection{Statement of problem}

While there seems to be growing evidence that some methods for providing corrective feedback may be more effective (Ferris, 2006), either approach may become less effective when students' writing are too long to be checked. This is because the huge number of errors can be overwhelming for the teacher to identify and seemingly tedious and frustrating for the students to correct. The same problem has been observed in Iranian EFL writing classes in schools, at universities and even in language institutes. As a result, neither the teacher nor the student may finish their job well. Therefore, there is a need to focus on the amount of writing to make it manageable for both of them.

Many studies have tried to investigate the effectiveness of different types of WCF especially in Iranian context (Jalali \& Abedi, 2011; Farrokhi \& Sattarpour, 2011; Hashemzade \& Mohammadnejad, 2012; Farrokhi \& Chehrazad, 2012. Considering majority of Iranian EFL learners, the researcher believes that they do not like to attend writing classes as they think writing classes are boring and useless. Most of the time, students studying in a language institute in Iran or in universities are asked to write paragraphs depending on the requirement of the course as home assignments, since in general Iranian EFL students are poor writers. Next the assignments are graded holistically in red marks that can be highly disappointing, but what is certain the teacher focus a lot on grammar. In fact, grammatical errors play a significant role in the grades obtained by the students. The researcher feels that writing teachers are more subjective. The case may differ when teachers are experienced and have rated writing for a long period of time. 
The researcher assumes that students may welcome the feedback which helps them improve their writing and motivate them to write better. Actually, they like their writing to be meaningful. It appears that providing correct answers to the errors is not helpful since students may not pay attention to the corrections made by the teacher. They need a meaningful feedback which can raise their linguistic awareness and give them an opportunity to think about the errors and correct them. Therefore, administrating error codes may seem appropriate for they need as they have to distinguish the error types and correct it by themselves.

Another challenge associated with Iranian EFL learners' writing can be attributed to the fact that they are not exposed to writing every session. They may probably write few compositions during a term. For example, taking the New Interchange books into consideration, most students in language institutes are asked to write only one piece of writing for each unit. In other words, one small piece of writing is completed in every four session. This highlights the fact that writing is not something continuous and perhaps the feedback on the writing may be stopped several times during the term as there is no writing. Therefore, a need for a constant writing is felt in the present context.

Considering all these dilemmas, the researcher believes that there is a need for a new writing instruction and feedback strategy to be used for Iranian EFL learners to help them improve their writing. It seems that both teachers and learners would benefit from an approach that would focus on shorter writings, fewer corrections along with more frequent feedback. Such an approach to writing pedagogy has been used by Hartshorn (2008) and it has shown some promise in helping students improve their writing. The main phase in this approach is a 10-minute writing completed at the beginning of each class period. Because the writing is short in length, the teacher is able to provide corrective feedback by the next class period. Moreover, since the writing has a manageable size, the student may be able to process it easily.

Therefore, dynamic WCF and direct WCF have been chosen to examine if they may leave any significant effect on the writing improvement. Following that, the researcher was trying to figure the type of feedback that would best suit Iranian learners for fulfilling their needs to better writing.

The following research question will be addressed in this study:

1- Does dynamic WCF leave any significant impact on the improvement of learners' writing?

2- Does direct WCF leave any significant impact on the improvement of learners' writing?

3- Is there any difference between students who receive dynamic WCF and direct WCF regarding their writing improvement?

\section{Methodology}

\subsection{Participants}

This study was conducted in a Language Institute in Iran on Iranian elementary English students. Elementary level students were chosen because the number of students in girls' and boys' section suited the present study. At the very beginning, the researcher had planned to carry out the research using three groups, two experimental groups and one control group. However, due to the fact that the number of participants did not meet the researcher's requirements, she had to ignore control group. It is noteworthy; that the researcher was dealing with the same students earlier in the beginners levels and therefore decided not to have the control group. Thus the intake was the whole class that was divided into two groups A and B that would function as experimental groups in the study. The main objective was to explore the differences between the two groups which were supposed to receive the treatments. As a result, the students were divided into two groups. Group A consisted of 24 students (girls $=14$ and boys $=10$ ) ranging from 15 to 31 years (with a mean of 19.12 years), and group B included 20 students (girls $=9$ and boys $=11$ ) ranging from 16 to 30 years (with a mean of 22 years). Majority of learners were taking English classes for one consecutive year.

The students passed Interchange (Intro) successfully and were studying interchange one. They were planned to study the first eight units of this book that term (fall 2013). Due to some limitations imposed by the institute, the researcher was not allowed to give a proficiency test because the manager claimed that all the students of that institute were in the same level of proficiency as they all passed the placement test given by the institute. However, the researcher decided to consider the participants' pretest as a source of homogeneity and therefore concluded that they were almost of the same level of proficiency in English except for five students who were ignored in the study at the end. Besides the researcher, two teachers who were both MA students in English and had the experience of five years in teaching helped her with correcting the papers and controlling the error corrections made by the researcher to ensure that all items were considered accurately.

\subsection{Instrument}

This study implemented a pre-test and post-test to obtain the necessary data on subjects' capability in writing. To obtain data on the pre-test, the teacher read a short story chosen from Anecdotes in American English by L. A. Hill (1980) in the class. The students were supposed to listen to it and were asked to write the summary within 20 minutes in the class. The purpose of this pre-test was to make sure that all the participants have the same capability in paragraph writing. The writings were checked by the researcher and two other teachers who double checked the items by applying Brown and Baily's 1983 analytic scale for rating composition task. As mentioned earlier, in addition to a paragraph writing task as a pretest, learners' grades in previous term were also considered a reason to check the homogeneity of the groups. The final exam was composed of 50 multiple choice items on listening, vocabulary, grammar and reading (listening and reading each 10 items, vocabulary and grammar each 15 items). The objective of the test was to evaluate the proficiency of learners in all skills they had learned during the term. The test was considered a standard one and its reliability and 
validity were checked. Using another short story from the same book, the similar writing task was given to the students as the post-test and the same scale was used for correction and controlled and checked by her colleagues.

\subsection{Sampling}

According to Birjandi and Mosallanejad (2010), sampling refers to the process of drawing samples. They believe sampling is a small selection from a population. Cluster sampling as one type of sampling was chosen for the current study as the researcher was not able to choose the participants randomly. Birjandi and Mosallanejad (2010) state that cluster sampling confines the researcher to limit the number of relatively compact geographical areas thus reducing the problems of traveling and related costs to a certain extent. Therefore, the researcher chose one language institute in Yazd (Taft). The students from elementary levels who were accessible to the researcher were chosen as the sample population.

\subsection{Design}

The study was conducted using a quasi-experimental method of research. Based on the definition of Birjandi and Mosallanejad (2010), quasi experimental research is used to approximate the conditions and standards of the true experiments as much as possible in a setting which does not allow the control or manipulation of all relevant variables. In this study, the researcher was not able to choose the subjects randomly. Seemingly, there was no control group due to the lack of students. Therefore, quasi experimental design was utilized for the present research. Using sampling cluster, the participants were divided into two experimental groups. The subjects in experiment Group A received dynamic written corrective feedback and the students received codes for their errors. For example, $\mathrm{N}=$ noun, Art $=$ article, $\mathrm{VT}=$ verb tense. For Group B, direct error correction was performed because this is the most commonly adopted strategy in Iranian English language practices. In both groups the instructor provided complete correct form of errors. Having three independent variables, dynamic WCF, direct error correction and gender, and one dependent variable, students' improvement in writing, the researcher conducted a quantitative research and used paired sample test and an independent sample T-test to analyze her data.

\subsection{Procedure}

In this quasi-experimental study, two groups A and B (boys and girls) of students participated. The classes were coed and they had approximately the same level of proficiency. A week prior to starting the treatment sessions, a writing test as a pre-test was given to all the participants in order to be sure of the homogeneity and to measure their writing ability at the beginning of the study. The participants in both groups listened to a short story read chosen from "Anecdotes in American English", Elementary level, and were asked to write a summary about 150-200 words within a given time (20-25 minutes). Afterward, over the next eight weeks, the two groups completed eight writing tasks as home assignments every week followed by a corrective feedback (CF) treatment session in the following class session. The writing assignments were written assignments on topics chosen by the researcher based on the units of Interchange One. Students were asked to write a paragraph about 100-150 words at home. Also, they were asked to consider the time (10-15 minutes for completing each writing) and do not ask for help.

Experiment group A received dynamic coded corrective feedback. In this group, the error codes were introduced and explained to the students at the beginning of the treatment by the teacher. These codes were a sign to the type of errors made by students. For example, whenever "SPG" was written under a word, it meant that an error of spelling had occurred. Then, the writings were checked and given back to the students. It is worth mentioning that the errors were underlined but the corrected forms were not provided for them. The relative codes were written next to each error to give a clue to the kind of errors.

On the other hand, the students in group B received direct error correction, the errors were corrected by the teacher and they were not supposed to make any correction. It is worth mentioning that the students' writings in both groups were corrected holistically before, giving some general comments or marks. However, in this study in order to check the writings the researcher used an analytic scale for rating the composition tasks ( Brown and Bailey scale for writing, 1983).

In this research, there were no grammatical targets for both groups and all the errors, semantic, structure and mechanical were checked by the researcher and two other teachers. After the teacher returned the marked paragraphs to group A, the students were asked to correct the marked errors and return the assignments in the next class. Since the primary focus of this study was on linguistic accuracy, emphasis was placed on editing (correcting the errors) rather than revision (changing the content). Students were given seven days time to redo their writing. The aim was to achieve an almost error-free version. The intent of having the students to produce such a version of the paragraph was to provide them with an opportunity to become more familiar with the linguistic rules and accurate writing. Moreover, they were given a deadline to keep the feedback manageable for both the teachers and students. Throughout this process, the responsibility of the teacher was to return edited drafts to the students. In addition to editing and keeping track of all these paragraphs, the researcher kept a running total of the type and frequency of the students' errors on a tally sheet, a cumulative list of errors that shows the frequencies for each types (cited in Hartshorn et. al, 2010).

The purpose of this sheet was to help the students to become well acquainted with their most frequent error types. It was hoped that with this heightened awareness, students would become more familiar with how to overcome their linguistic weaknesses so they could produce more accurate writing.

On the other hand, group B received direct written corrective feedback on their writings. In this group, the teacher underlined their errors and provided the correct form of them, and then the corrected writings were given back to them in order to make them aware of their errors and the corrected forms to improve their following writings. As mentioned 
before, the treatment lasted about 8 weeks. In total, each student was required to submit at least 8 writings which equals almost one every week. After this period, a post-test was given to the participants to measure the differential effect of dynamic corrective feedback and direct error correction on the improvement of students' writing. Similar to what was done for the pre-test, another short story was read to the class and the students in both groups were asked to write the summary about 150-200 words within the same time (20-25 minutes) in the class.

Both the pre-test and post-test writings were checked and scored based on analytic scale for rating composition task. Seemingly, in an effort to estimate the reliability of the measures investigated in this study, except the researcher, two experienced teachers rated the writings after undergoing a brief period of training and practicing. During this time, several meetings were held to discuss the specific criteria to be used to evaluate the writing.

\section{Data Analysis}

To answer the first question, that is to find out the effect of dynamic WCF on the improvement of learners' writing, a paired sample test was conducted to compare the pre-test and post-test writing scores in this group. Table 4.10 represents the results of the tests.

Table 1. Paired Samples Statistics of Dynamic WCF Group

\begin{tabular}{|c|c|c|c|c|c|}
\hline & & Mean & $\mathrm{N}$ & $\begin{array}{l}\text { Std. } \\
\text { Deviation }\end{array}$ & $\begin{array}{l}\text { Std. Error } \\
\text { Mean }\end{array}$ \\
\hline \multirow{2}{*}{ pair 1} & Pre & 15.2917 & 24 & 1.70623 & .34828 \\
\hline & Post & 17.4583 & 24 & 1.35066 & .27570 \\
\hline
\end{tabular}

As it can be observed in table 1, the students in the first experimental group who received dynamic WCF could show improvement in their writing. The post-test revealed enhancement in the mean score of this group. Having a short look at the above table reveals that students' mean score in post-test (17.45) has increased in comparison to their mean score in pre-test (15.29). Therefore, we can conclude that using this new strategy of error correction, students could improve their writing. To shed more light on this fact, i.e., improvement of learners in this group, and understand how effective dynamic WCF was, table 2 has been illustrated.

Table 2. Paired Sample Test for dynamic WCF group

\begin{tabular}{lllllllll}
\hline & Mean & Std. Deviation & $\begin{array}{c}\text { Std. Error } \\
\text { Mean }\end{array}$ & Lower & Upper & T & $\begin{array}{c}\text { Df } \\
\text { Sig.(2-tailed) } \\
.000\end{array}$ \\
\hline Pair 1 pre-post & -2.16667 & .70196 & .14329 & -2.46308 & -1.87025 & -15.121 & 23 & \\
\hline
\end{tabular}

As seen in table 2 the Sig. (2-tailed) is .000 . This has actually been rounded down to three decimal places- it means that the actual probability value was less than .005 . This value is substantially smaller than our specific alpha of .05 . Therefore, it can be concluded that there is a significant difference in the pre-test and post-test scores which shows the improvement of students who were given dynamic WCF on their writing.

Regarding the effectiveness of the dynamic WCF and findings of the first research question, this study can be considered in line with Hartshorn et. al., (2010). Utilizing a control group in his research, the result showed that writing of the experiment group which received dynamic WCF was significantly more accurate than the control group based on the analyses of pre-test and post-test writing. Seemingly, the result of the present work can be considered as a confirmation to Hartshorn et. al., (2011). In their study, they tested the effectiveness of dynamic WCF and came to this conclusion that the treatment group outperformed the contrast group regarding the type of feedback they received. However, it is worth mentioning that the result of the study must be evaluated with caution because no control group was used.

Seemingly, considering the first question, this study produced results which corroborate the findings of Evans and Hartshorn (2010). The data from holistic and analytical evaluation of their study indicate that students did improve their linguistic accuracy on new writing assignments when dynamic WCF strategy was implemented. These gains were quite pronounced between the writing samples taken from the beginning and end of the term. Nevertheless, Evans and Hartshorn (2010) hasten to add the result must be evaluated with caution because no control group was used.

To answer research question two, that is whether direct error correction may leave any significant impact on the improvement of students' writing, the same procedure was done for the second experimental group. In this connection, they were also read a short story before and after the treatment and later were asked to write the summary in the class. Taking a short look at table 3 and 4 reveals that the students in this group could also improve their writing after receiving the traditional direct corrective feedback. Considering their mean score in pre-test (14.85) and post-test 
(15.80), we came to this conclusion that the students in direct group could relatively improve their writing after receiving the feedback.

Table 3. Paired Samples Statistics for direct EC group

\begin{tabular}{rrrrrr}
\hline & Mean & N & Std. Deviation & Std. Error Mean \\
\hline & Pre & 14.8500 & 20 & 1.72520 & .38577 \\
pair 1 & & & & & \\
& Post & 15.8000 & 20 & 1.43637 & .32118 \\
\hline
\end{tabular}

Table 3 is quite revealing that students in this group could do better in the post-test after receiving direct error correction on their writings. However, the increase in the mean score is not as significant as the students who were given dynamic WCF

Table 4. Paired Sample Test for direct error correction group

\begin{tabular}{lcccccccc}
\hline & Mean & $\begin{array}{c}\text { Std. } \\
\text { Deviation }\end{array}$ & $\begin{array}{c}\text { Stn. Error } \\
\text { Mean }\end{array}$ & Lower & Upper & t & $\begin{array}{c}\text { df } \\
\text { Sig. (2- } \\
\text { tailed) }\end{array}$ \\
\hline Pair 1 pre-post & -.95000 & .82558 & .18460 & -1.33638 & -.56362 & -5.146 & 19 & .000 \\
\hline
\end{tabular}

Like the previous group, table 4 reveals that Sig. (2-tailed) equals .000. The same reason can be mentioned here that as the probability value was less than .005 , the Sig. has been rounded down to three decimal places. This value is substantially smaller than our specified alpha of .05. Therefore, we can conclude that there is a significant difference in the pre-test and post-test score of this group which highlight the fact that this treatment was also useful for the learners' writing improvement.

In this connection, the findings of second research question is in agreement with Beuningen, Jong and Kuiken's (2008) findings which showed that direct feedback proved to have a significant long-term effect. In their study, the effectiveness of direct and indirect corrective feedback was compared to the effect of two control treatments: a treatment that offered students an extra opportunity to practice their writing skill and a treatment in which students selfcorrected their errors without any available feedback. Later, they found that although indirect feedback was somehow effective, direct feedback left more significant on students' writing.

Seemingly, the results also support the idea of Abedi, Latifi and Moinzadeh (2010) that providing students with direct corrective feedback can also be effective. However, comparing two feedback strategies (error correction vs. error detection), the result of their study suggested that error detection along with the codes led to better improvement in learners' writing that direct error corrective treatment. Taking all these results into consideration, there is some evidence to suggest that the students who are given direct error correction on their errors may be able to use the receiving feedback in the best way to decrease their errors and produce an acceptable composition. However, we should not forget that the feedback strategies that incite learners' awareness appear to be more effective.

To answer the third research question which is whether students in dynamic WCF group improve in their writing more than students exposed to traditional direct error correction an independent sample T-test was administered using the post-test scores of two groups to see which group could do better performance. See table 5 and 6 for more information:

Table 5. Mean score of the post-test for both groups

\begin{tabular}{lllrrr}
\hline & Group & N & Mean & Std. Deviation & \multicolumn{2}{c}{ Std. Error Mean } \\
\hline \multirow{3}{*}{ Post } & Dynamic & 24 & 17.4583 & 1.35066 & .27570 \\
& Direct & 19 & 15.8421 & 1.46299 & .33563 \\
\hline
\end{tabular}

It is apparent from table 5that dynamic group had better performance in the post-test due to the new strategy they were given. Considering the mean score of two groups ( dynamic $=17.45$ and direct $=15.84$ ), the findings show that students who received dynamic WCF as the treatment could outperformed the second group who were given direct error correction on the writings.

Seemingly, from the data in table 6 , it is obvious that which group did better regarding the feedback given to them. 
Table 6. Independent Samples Test of both groups

\begin{tabular}{cccccccccc}
\hline & & & & & $\begin{array}{l}\text { Sig. (2- } \\
\text { tailed) }\end{array}$ & $\begin{array}{l}\text { Mean } \\
\text { Difference }\end{array}$ & $\begin{array}{l}\text { Std. Error } \\
\text { Difference }\end{array}$ & Lower & Upper \\
\hline $\begin{array}{l}\text { Equal variances } \\
\text { assumed }\end{array}$ & .007 & .933 & .757 & 1 & .001 & 1.61623 & .43025 & .74733 & 2.48513 \\
$\begin{array}{l}\text { Post } \\
\quad \begin{array}{l}\text { Equal variances } \\
\text { not assumed }\end{array}\end{array}$ & & .721 & 7.223 & .001 & 1.61623 & .43435 & .73633 & 2.49613 \\
\hline
\end{tabular}

As mentioned earlier, an independent sample t-test was conducted to compare the mean score for two groups. There was a significant difference in scores for dynamic group $(\mathrm{M}=17.45, \mathrm{SD}=1.35)$ and direct group $(\mathrm{M}=15.84, \mathrm{SD}=1.46)$. the results, as shown in table4.15, indicate that the first group (dynamic) could improve in their writing more than the second group (direct) as the Sig. (2-tailed=.001). Therefore, the finding is in agreement with that found by Evans and Hartshorn(2010). It also supports the idea of Hartshorn (2008) that dynamic WCF may leave more impact on learners' writing than traditional error correction instruction.

Taking all these results into consideration, it can be said that research questions one, two and three have been answered. To put it simply, according to the results, dynamic WCF left significant impact on learners' writing ability (Q 1). Seemingly, the subjects in the second group who received direct WCF improved in their writing regarding the feedback they received (Q 2). However, it should be noted that the first treatment group, i.e., dynamic WCF, could outperformed the second group in the case of receiving two types of feedback (Q3).

\section{Conclusion}

Although writing ability is one of the most important outcomes of higher education, many L2 writer students try hard to produce error-free writings. While some researchers like Truscott $(1996,1997)$ have claimed that error correction is ineffective and even harmful to learners, others believed that providing feedback may be beneficial for students (Bitchener \& Cameron, 2005; Ferris, 2004). However, there are still discussions over the evidence of the value of corrective feedback. Therefore, the aim of this study was to contribute to this line of research by investigating the efficacy of one innovative approach to L2 writing. The assumptions were that if feedback were more manageable, timely, meaningful and constant, accuracy might improve.

Additionally, the present study attempted to determine whether two different feedback strategies- direct error correction and dynamic written corrective feedback- would yield different results for the improvement of Iranian elementary learners' writing regarding the number of errors they committed in their writings.

The purpose of this study was to determine the effect of one approach to writing pedagogy on L2 writing improvement. Using two experimental groups, the first group was given dynamic WCF, an innovative approach that aimed to improve writing by raising learner awareness through error correction, while the second group received traditional direct error correction,. This was obtained through a systematic approach where students were asked to write short paragraphs every session within specific time (15 minutes) as home assignments. Later, the students in the first group received dynamic WCF feedback on their writings, follow their progress through tally sheets, and worked toward utilizing what they learned in new compositions. However, the students in the second group were given direct error correction on their writing meaning that they were provided with correct form of errors.

Using paired sample test for both groups, the results revealed significant improvements in their writing. However, dynamic group could improve their writing ability better than direct group. Therefore, the present study provides evidence that all error categories specifically grammatical errors can be improved through error correction. Seemingly, L2 writers may benefit the most when feedback designed to improve their writing is manageable, meaningful, timely and constant.

Though additional research is needed to further clarify how best to use teaching and learning opportunities to improve L2 writing, this study may give hope to teachers and students who are seeking to change the atmosphere of writing classes and change it into a where students do not get frustrated and bored.

\section{Refrences}

Abedi, R., Latifi, M., \& Moinzadeh, A., (2010). The Effect of Error Correction vs. Error Detection on Iranian EFL Learners' Writing Achievement. English Language Teaching, Vol.3, No. 4, pp. 168-174.

Ashwell, T. (2000). Patterns of teacher response to student writing in a multiple draft composition classroom: Is content feedback followed by form feedback the best method? Journal of Second Language Writing, Vol. 9, pp

227-257. 
Beuningen, C.G, Jong, N. H., \& Kuiken, F. (2008). The Effect of Direct and Indirect Corrective Feedback on L2

Learners' Writing Accuracy. Experimental and intervention studies, pp: 279-296.

Beuningen, C., (2010). Corrective Feedback in L2 Writing: Theoretical Perspective, Empirical Insights, and Future Direction. International Journal of English Studies, Vol. 10(2), pp. 1-27.

Bitchener, J., \& Knoch, U., (2008). The Value of Written Corrective Feedback for Migrant and International Students. Language Teaching Research, Vol. 12(3), pp. 409-431.

Bitchener, J., Young, S., \& Cameron, D., (2005). The effect of Different types of Corrective Feedback on ESL students’ Writing. Journal of Second language Writing.Vol. 14, pp. 191-205.

Chandler, J., (2003). The Efficacy of Various Kinds of Error Feedback for Improvement in the Accuracy and Fluency of L2 Student Writing. Journal of Second Language Writing, Vol. 12, pp. 267-296.

Corpuz, V., (2011). Error Correction in Second Language Writing: Teacher's Beliefs Practices and Students' Performance. (Unpublished Master dissertation). Queensland University of Technology, Australia.

Erel, s. \& Bulut, T. (2007). Error Treatment in L2 Writing: A comparative study of direct and indirect coded feedback in Turkish context. Journal of Social Science Institute, Vol. 1, pp. 379-415.

Evans, N., Hartshorn, K.J., Mc Collum, R., \& Wolfersberger, M., (2010). Contextualizing Corrective Feedback in Second Language Writing Pedagogy.Language Teaching Research, Vol. 14(4), pp. 445-463.

Evans, N., Hartshorn, J., \& Strong, D., (2011). The Efficacy of Dynamic Written Corrective Feedback for University-Matriculated ESL Learners. System, Vol. 33, pp. 229-239.

Farrokhi, F., \& Chehrazad, M., (2012). The Effects of Planned Focused on Form on Iranian EFL Learners' Oral Accuracy. World Journal of Education, Vol. 2, No. 1,pp. 70-81.

Farrokhi, F., \& sattarpour, S., (2011). The Effects of Focused and Unfocused Written Corrective Feedback on Grammatical Accuracy of Iranian EFL Learners. Theory and Practice in Language Studies, Vol. 1, No. 12, pp. 1797-1803.

Ferris, D. (1999). The case for Grammar Correction in L2 Writing classes: A response to Truscott (1996). Journal of Second Language Writing, Vol. 8, 1-11.

Ferris, D. (2004). The "Grammar Correction" debate in L2 writing: Where are we, and where do we go from here? (and what do we do in the meantime...?). Journal of Second Language Writing, Vol. 13, pp. 49-62.

Hartshorn, J., (2008). The Effects of manageable Corrective Feedback on ESL Writing Accuracy. (Unpublished Doctoral Dissertation). Brigham Young University. United States.

Hartshorn, K.J., Evans, N., Merrill, P., Sudweeks, R., Strong, D., \& Anderson, N., (2010). Effects of Dynamic Corrective Feedback on ESL Writing Accuracy. TESOL Quarterly, Vol. 44, No. 1, pp. 84-109.

Hashemzadeh, H., \& Mohammadnejad, S., (2012). A Case for Direct and Indirect Feedback. The Other Side of Coin. English Language Teaching,Vol. 5, No. 3, pp. 230-239.

Mahmood, A., (2000). Coded Corrective Feedback: In search of a Compromise. TESL Reporter, Vol. 33(2), pp. 10- 17 .

Sheen, Y., (2007). The Effect of Focused Written Corrective Feedback and Language Aptitude on ESL Learners' Acquisition of Articles. TESOL Quarterly, Vol. 41, No. 2, pp. 255-183.

Truscott, J., (1996). The Case Against Grammar Correction in L2 Writing Classes. Language Learning, Vol. 46(2), pp. 327-369. 


\section{Indirect Coding Symbols}

$\begin{aligned} D & =\text { Determiner } & S / P L & =\text { Singular/Plural } \\ S V & =\text { Subject Verb Agreement } & C / N C & =\text { Count } \text { Noncount } \\ V F & =\text { Verb Form } & ? & =\text { Meaning is not clear } \\ r O & =\text { Run-on Sentence } & A W K & =\text { Awkward Wording } \\ \text { inc } & =\text { Incomplete Sentence } & & =\text { Word Order } \\ V T & =\text { Verb Tense } & C & =\text { Capitalization } \\ P P & =\text { Preposition } & P & =\text { Punctuation } \\ S P G & =\text { Spelling } & -Q & =\text { Omit } \\ W F & =\text { Word Form } & \Lambda & =\text { Something is missing } \\ W C & =\text { Word Choice } & \# & =\text { New Paragraph }\end{aligned}$

Appendix 2. Tally Sheet

\begin{tabular}{|c|c|c|c|c|c|c|c|c|c|c|c|c|}
\hline Symbols & 1 & 2 & 3 & 4 & 5 & 6 & 7 & 8 & 9 & 10 & 11 & 12 \\
\hline D & & & & & & & & & & & & \\
\hline SV. & & & & & & & & & & & & \\
\hline VF. & & & & & & & & & & & & \\
\hline RO. & & & & & & & & & & & & \\
\hline Inc. & & & & & & & & & & & & \\
\hline VT. & & & & & & & & & & & & \\
\hline PP. & & & & & & & & & & & & \\
\hline SPG. & & & & & & & & & & & & \\
\hline WF & & & & & & & & & & & & \\
\hline WC. & & & & & & & & & & & & \\
\hline S/PL. & & & & & & & & & & & & \\
\hline C/NC & & & & & & & & & & & & \\
\hline ? & & & & & & & & & & & & \\
\hline AWK. & & & & & & & & & & & & \\
\hline - & & & & & & & & & & & & \\
\hline C & & & & & & & & & & & & \\
\hline P & & & & & & & & & & & & \\
\hline
\end{tabular}

